\title{
Removal of cadmium ions by the marine diatom Phaeodactylum tricornutum Bohlin accumulation and long-term kinetics of uptake
}

\author{
E. Torres, A. Cid, C. Herrero, J. Abalde \\ Laboratorio de Microbiología, Facultad de Ciencias, Universidad de A Coruña, Campus da \\ Zapateira s/n, 15071 A Coruña, Spain
}

Bioresource Technology

Volume 63, Issue 3, March 1998, Pages 213-220

Received 10 July 1997, Revised 10 September 1997, Accepted 22 September 1997, Available online 19 June 1998

DOI: 10.1016/S0960-8524(97)00143-0

\begin{abstract}
The marine diatom Phaeodactylum tricornutum Bohlin was exposed to different cadmium concentrations (1-100 $\left.\mathrm{mg} \mathrm{l}^{-1}\right)$ for 4 days. The amount of cadmium removed was recorded, with particular attention paid to long-term uptake kinetics, and to the cellular location of cadmium. Cadmium accumulation occurred at all concentrations assayed. The $E_{50}$ of cadmium to $P$. tricornutum was $22.39 \mathrm{mg} \mathrm{I}^{-1}$ after 4 days of exposure. Cadmium uptake followed a saturation kinetic at cadmium concentrations $\geq 25 \mathrm{mg} \mathrm{I}^{-1}$. However, at lower cadmium concentrations, the uptake of this metal followed a linear trend for all days of culture. At cadmium concentrations in the medium lower than $25 \mathrm{mg} \mathrm{I}^{-1}$, P. tricornutum removed cadmium mainly within the cell. At higher cadmium concentrations, the amount of cadmium removed by adsorption to the cell surface was higher than intracellular cadmium, because of the toxic effects of cadmium on $P$. tricornutum cells. This toxicity reduced the cadmium accumulation within the cells.
\end{abstract}

\section{Keywords}

Cadmium; removal; marine diatom; accumulation; kinetics 


\section{Introduction}

Recent industrialization in coastal regions has increased the discharge of industrial wastes, especially those containing heavy metals, into marine waters (Wikfors and Ukeles, 1982). Industrial and mining effluents can contain extremely high concentrations of metals. These contaminants have been found to be some of the most toxic pollutants. Continued anthropogenic input of metals into the marine environment has increased the concentrations of these metals to alarming levels. Thus, the effects of heavy metals on the marine ecosystem are of particular interest because, unlike other pollutants, metals persist without degradation. Marine algae are the first organisms to be exposed to this pollution. The effects of heavy metals on phytoplankton are especially significant since these organisms constitute the base of the marine food chain.

Cadmium is a heavy metal recognized as one of the most hazardous environmental pollutants. It is a non-essential and non-beneficial element to organisms, causing toxicity; for this reason, the development of systems for removing this metal from polluted areas is necessary. Conventional methods for removing metals include chemical processes, but other methods are based on biological systems. For example, cadmium can be taken up by phytoplankton and can be accumulated by these microalgal cells. The ability of phytoplankton to concentrate trace metals such as cadmium, copper, zinc or lead from seawater is well known. Moreover, phytoplankton are able to accumulate large amounts of cadmium despite its low concentration in seawater (Schulz-Baldes and Lewin, 1976). This ability can be used for the removal of cadmium from seawater.

The accumulation of heavy metals by phytoplankton in laboratory cultures has been the focus of numerous studies, because some microalgal species can be used for the removal of metals from industrial- waste solutions (Ross, 1986). Many studies have been done on essential heavy metals (Garnham et al., 1992; Gnassia-Barelli and Romeo, 1987; Xue and Sigg, 1990), but studies on the removal of non-essential metals, like cadmium, are of particular interest because these elements are very toxic at low concentrations (Fehrmann and Pohl, 1993; Jennings and Rainbow, 1979; Li, 1980). The amount of metal removed is dependent on the microalgal species and tolerant algae can take up high amounts of metals.

The ability and suitability of the marine diatom Phaeodactylum tricornutum to remove cadmium from a solution containing different concentrations of this metal under standard laboratory conditions were investigated. Long-term uptake kinetics and the patterns of cellular distribution of cadmium during the exposure time were also studied. Three fractions were established: intracellular cadmium, cadmium removed by adsorption to the cell surface and total cadmium removed. Cell growth was considered as a parameter to monitor the toxic effect of cadmium on $P$ tricornutum. 


\section{Methods}

\section{Organism and growth conditions}

The microalga used was the marine diatom Phaeodactylum tricornutum Bohlin supplied by Dr. J. Fábregas (University of Santiago, Spain). The main interest of this microalga lies in its ability to adapt easily to environmental factors and because it is one of the algae more tolerant to heavy metal pollution (Bonin et al., 1986).

Phaeodactylum tricornutum cells were cultured in batch conditions in natural organic-free seawater. The seawater was passed through a Millipore filter of pore size $0.45 / \mu \mathrm{m}$ and a charcoal column to eliminate organic chelating substances, and sterilized at $121^{\circ} \mathrm{C}$ for $20 \mathrm{~min}$. The assays were carried out in this unenriched seawater. The seawater had a salinity of $35 \%$; and initial $\mathrm{pH}$ of 8-2.

A stock solution of cadmium was prepared by dissolving $\mathrm{CdCl}_{2}$ in Milli-Q water to give a final concentration of $10 \mathrm{~g}^{-1}$ of $\mathrm{Cd}^{2+}$. For the experiment, appropriate volumes of stock solution were added to seawater to obtain cadmium concentrations of $1,5,10,25,50,75$ and $100 \mathrm{mg} \mathrm{I}^{-1}$ Control cultures without cadmium were also included.

Cultures were carried out in triplicate in bottles (PYREX) containing $500 \mathrm{ml}$ of seawater. The bottles had previously been rinsed with $10 \%$ nitric acid for $24 \mathrm{~h}$ and finally rinsed several times

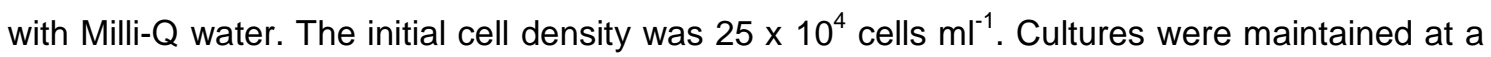
constant temperature of $18 \pm 1^{\circ} \mathrm{C}$ and under illumination of $68 \mu \mathrm{E} \mathrm{m}^{-2} \mathrm{~s}^{-1}$, with a dark:light cycle of $12: 12 \mathrm{~h}$, for 4 days. Cultures were gently shaken every day to ensure homogeneous exposure to the metal.

\section{Determination of P. tricornutum growth}

Growth of the microalgal cultures was measured daily by counting culture aliquots in a Neubauer haemocytometer. Growth rates were calculated from these data and expressed as doublings per day. The $\mathrm{EC}_{50}$ value (effective concentration: concentration of cadmium which reduces the population growth to $50 \%$ of the control growth level) was calculated by the method of probit analysis (Finney, 1964).

\section{Determination of the cadmium accumulation by P. tricornutum cells}

Determination of the cadmium removed by the microalga P. tricomutum was made by atomic absorption spectrophotometry using a modified method described by Stauber and Florence (1985).

Two aliquots of each culture exposed to the different cadmium concentrations were taken daily: one aliquot was used to determine the total cadmium removed, the other to determine intracellular cadmium. Total cadmium removed was determined by filtration of one culture 
aliquot through two superimposed 1-2 $\mu \mathrm{m}$ MF-MiUipore filters. Each filter was digested with $1 \mathrm{ml}$ of $15 \mathrm{M} \mathrm{HNO} 3$ and $0.5 \mathrm{ml}$ of $72 \% \mathrm{HClO}_{4}$ to strong fumes of $\mathrm{HClO}_{4}(24 \mathrm{~h})$ and then diluted with an appropriate volume of Milli-Q water. Cadmium was determined in the solution obtained from each filter by atomic absorption spectrophotometry using a Perkin Elmer spectrophotometer. The lower filter was used as a blank. Intracellular cadmium was determined on the other culture aliquot. Cells were centrifuged at $4000 \mathrm{xg}$ for $5 \mathrm{~min}$ and the cellular pellet was resuspended in cadmium-free seawater containing $0.02 \mathrm{~m}$ EDTA. The EDTA removes cadmium adsorbed onto the surface of the algal cells, which allows only the intracellular cadmium to be measured. After $20 \mathrm{~min}$, the cells were centrifuged and the cell pellet digested and analyzed as for the measurement of total cadmium.

Cadmium adsorbed onto the surface of algal cells was determined by subtracting the intracellular cadmium concentration from the total cadmium concentration removed (adsorbed cadmium $=$ total cadmium - intracellular cadmium).

\section{Results}

\section{Growth}

Fig. 1 shows the growth curves obtained for $P$. tricornutum exposed to the different concentrations of cadmium. Data were statistically analyzed by ANOVA and Duncan's test $(\alpha=$ 0.05). The statistical analysis showed that there was a significant effect on growth of $P$ tricornutum at cadmium concentrations of $\geq 5 \mathrm{mg} \mathrm{I}^{-1}$. There were no significant differences between control cultures without cadmium and cultures with $1 \mathrm{mg} \mathrm{I}^{-1}(P<0.01)$, showing that this cadmium concentration was not inhibitory to $P$ tricornutum growth. As the cadmium concentration increased in the medium, total growth decreased. Growth rates also decreased as cadmium concentration in the medium increased and maximum growth rates were obtained in control cultures and in cultures with $1 \mathrm{mg}^{-1}$ of cadmium (Table 1).

The $\mathrm{EC}_{50}$ value calculated for this microalga after 4 days of exposure to cadmium was $22.39 \mathrm{mg}$ $\mathrm{I}^{-1}$. 


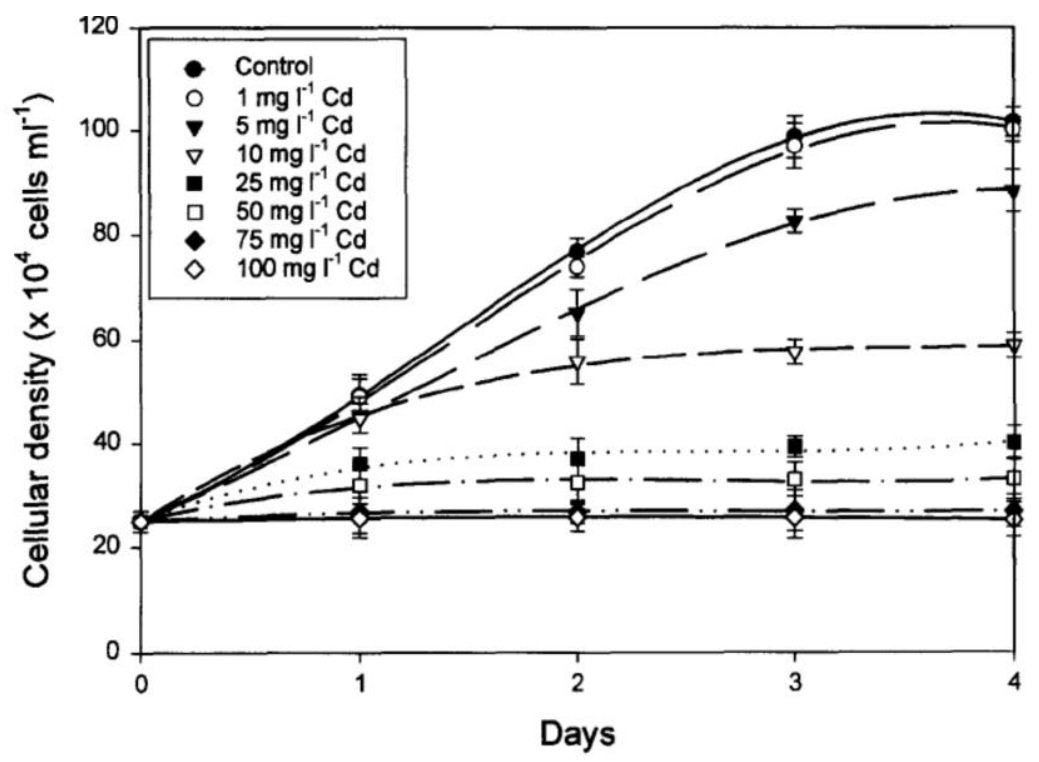

Fig. 1. Growth curves of $P$. tricornutum cells exposed to different cadmium concentrations.

\section{Cadmium accumulation}

Phaeodactylum tricornutum cells are able to accumulate cadmium both intracellularly and adsorbed onto the cell surface. Figure 2 shows the total amount of cadmium removed by this microalga as a function of the time of exposure and at different cadmium concentrations in the medium. Over the range of cadmium concentrations tested, the total amount of cadmium removed by $P$. tricornutum cells increased in proportional to the concentration of cadmium applied. In cultures with lower cadmium concentrations (1,5 and $\left.10 \mathrm{mg} \mathrm{l}^{-1}\right)$, total cadmium removal was linear; thus the cadmium concentration in the cells increased during the culture period. However, in cultures with higher cadmium concentrations, the linear increase occurred only for the first 2 days of culture, after which a plateau was reached. In cultures with 75 and $100 \mathrm{mg} \mathrm{I}^{-1}$ of cadmium, although there was no growth (Fig. 1), cadmium was continuously removed.

The highest level of metal removal occurred in cultures with the highest cadmium concentration $\left.\left(100 \mathrm{mg} \mathrm{I}^{-1}\right]\right)$ and on the third day of culture $\left(0.95 \pm 0.07 \mu \mathrm{g}\right.$ cadmium per $10^{6}$ cells).

Fig. 3 shows the amount of cadmium removed by uptake of the metal into the P. tricornutum cells (intracellular cadmium). In cultures with lower cadmium concentrations (1,5 and $10 \mathrm{mg} \mathrm{I}^{-}$ ${ }^{1}$ ), intracellular cadmium increased linearly as a function of time of exposure. In cultures with higher cadmium concentrations, this linear increase occurred for the first 2 days and thereafter the intracellular cadmium decreased. This decline was proportional to the cadmium concentration in the medium, being greatest in cultures with $100 \mathrm{mg} \mathrm{I}^{-1}$. Although in cultures with 75 and $100 \mathrm{mg} \mathrm{l}^{-1}$ of cadmium there was total inhibition of growth (Fig. 1), cadmium was accumulated within the cells until the second day of culture. The highest amount of cadmium 
removal by uptake into the cells occurred in cultures with $25 \mathrm{mg} \mathrm{I}^{-1}$ and on the third day of culture $\left(0.24 \pm 0.01 \mu \mathrm{g}\right.$ cadmium per $10^{6}$ cells $)$.

\begin{tabular}{lcccccccr} 
& Control & \multicolumn{7}{c}{ Cadmium concentration $\left(\mathrm{mg} \mathrm{1}^{-1}\right)$} \\
\cline { 3 - 9 } & & 1 & 5 & 10 & 25 & 50 & 75 & 100 \\
\hline Growth rate $\left(\right.$ day $\left.^{-1}\right)$ & 0.658 & 0.646 & 0.568 & 0.392 & 0.199 & 0.091 & $\sim 0$ & $\sim 0$
\end{tabular}

Table 1. Growth rates (day -I) of P. tricornutum cells exposed to different cadmium concentrations for 4 days

Fig. 4 shows the amount of cadmium removed by adsorption to the cell surface. The amount of cadmium removed by this mechanism increased during the culture period and at all cadmium concentrations. This increase was greater at high cadmium concentrations. As with total cadmium removal, cadmium removed by adsorption was also highest in cultures with 75 and $100 \mathrm{mg} \mathrm{I}^{-1}$. In these cultures there was no cell growth but cadmium was continuously adsorbed. The maximum amount of cadmium removed occurred in the culture with $100 \mathrm{mg} \mathrm{I}^{-1}$ after 4 days of exposure $\left(0.092 \pm 0.03 \mu \mathrm{g}\right.$ of cadmium removed per $10^{6}$ cells $)$.

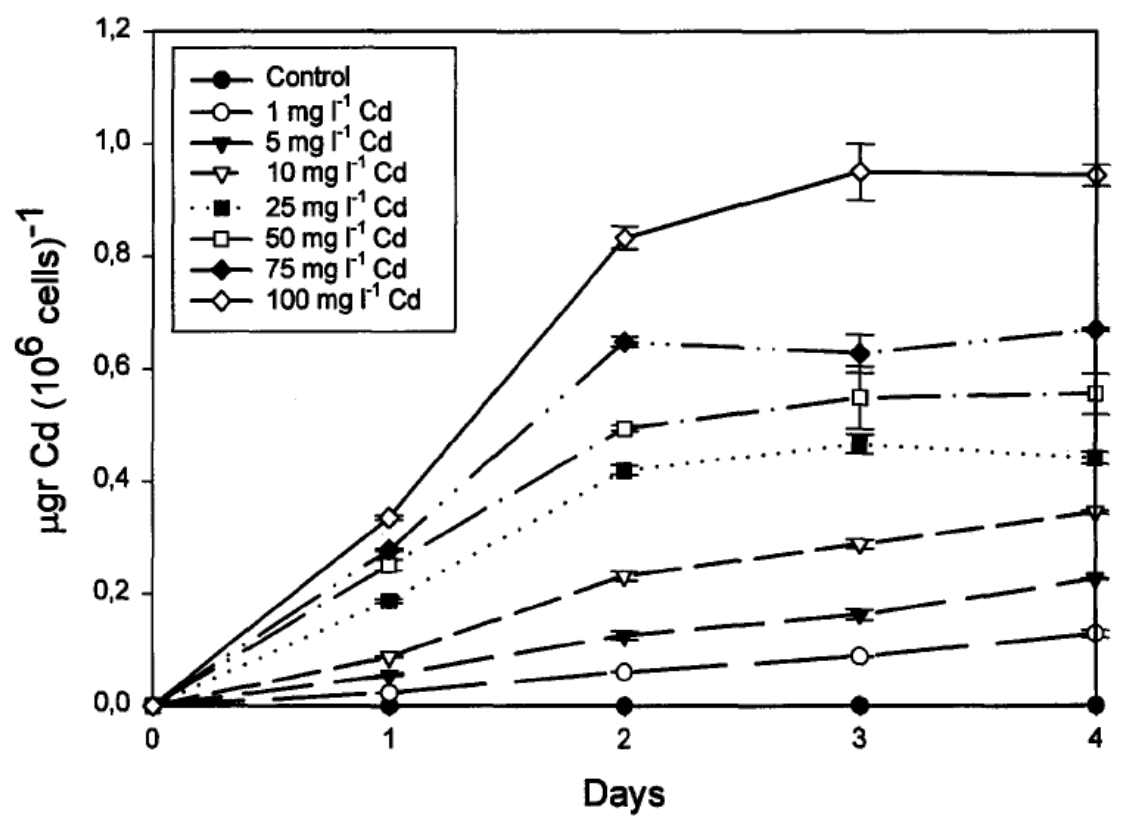

Fig. 2. Total cadmium removed by P. tricornutum cells exposed to different cadmium concentrations in the medium as a function of time of exposure. 


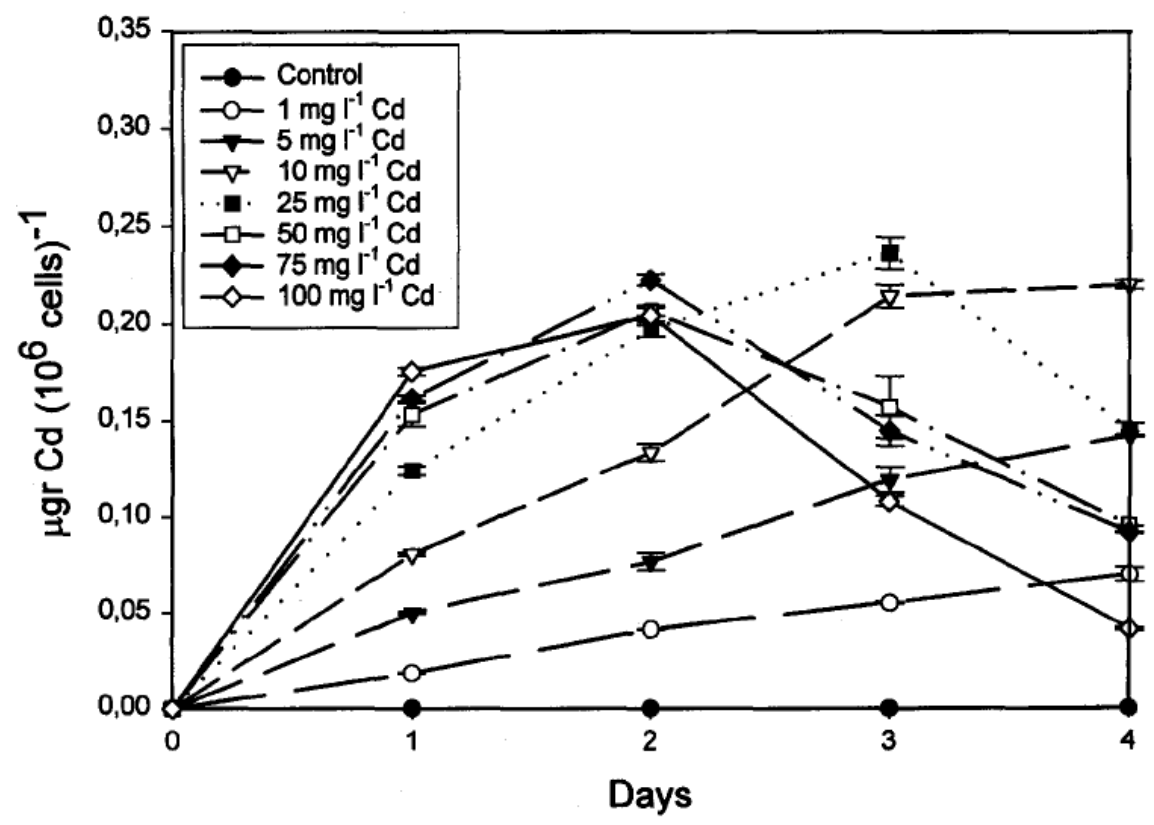

Fig. 3. Cadmium removed by uptake of the metal into $P$. tricornutum cells (intracellular) as a function of time of exposure.

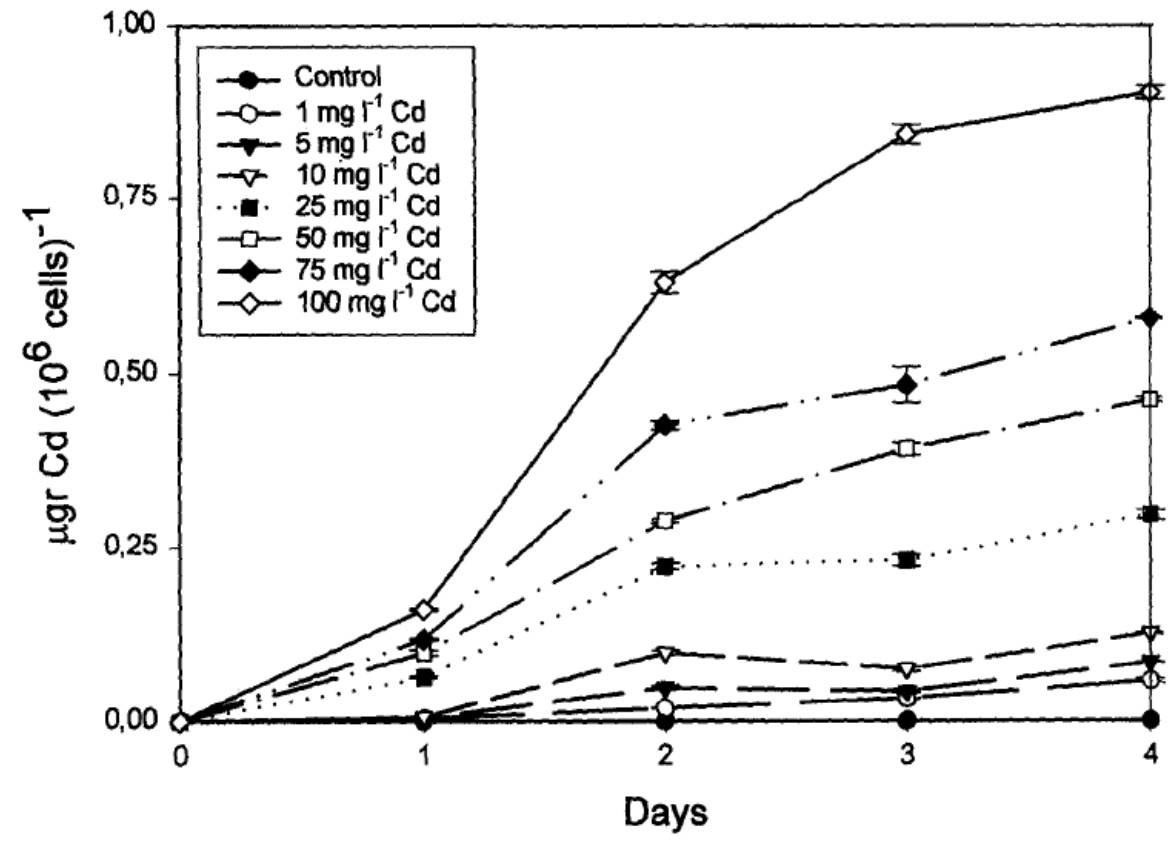

Fig. 4. Cadmium removed by adsorption onto the cell surface of $P$. tricornutum as a function of time of exposure,

In Fig. 5, intracellular cadmium, adsorbed cadmium and total cadmium removed by $P$ tricornutum cells are shown as a function of the concentration of cadmium in the medium, for each day of culture. On the first day of exposure, the highest amount of cadmium was located within the cells for all cadmium concentrations assayed. However, on the second day in cultures with $25 \mathrm{mg} \mathrm{I}^{-1}$ of cadmium or higher, the cadmium adsorbed to the cell surface became higher than intracellular cadmium. This difference increased as the cadmium concentration in the 
medium increased. This fact became more obvious in the following days of culture. Intracellular cadmium decreased with time, and this decline was greater as the cadmium concentration in the medium increased. However, at low cadmium concentrations $\left(<25 \mathrm{mg} \mathrm{I}^{-1}\right)$, intracelular cadmium was always higher than adsorbed cadmium. This means that at low cadmium concentrations cadmium removal was mainly by uptake of the metal into the cell.
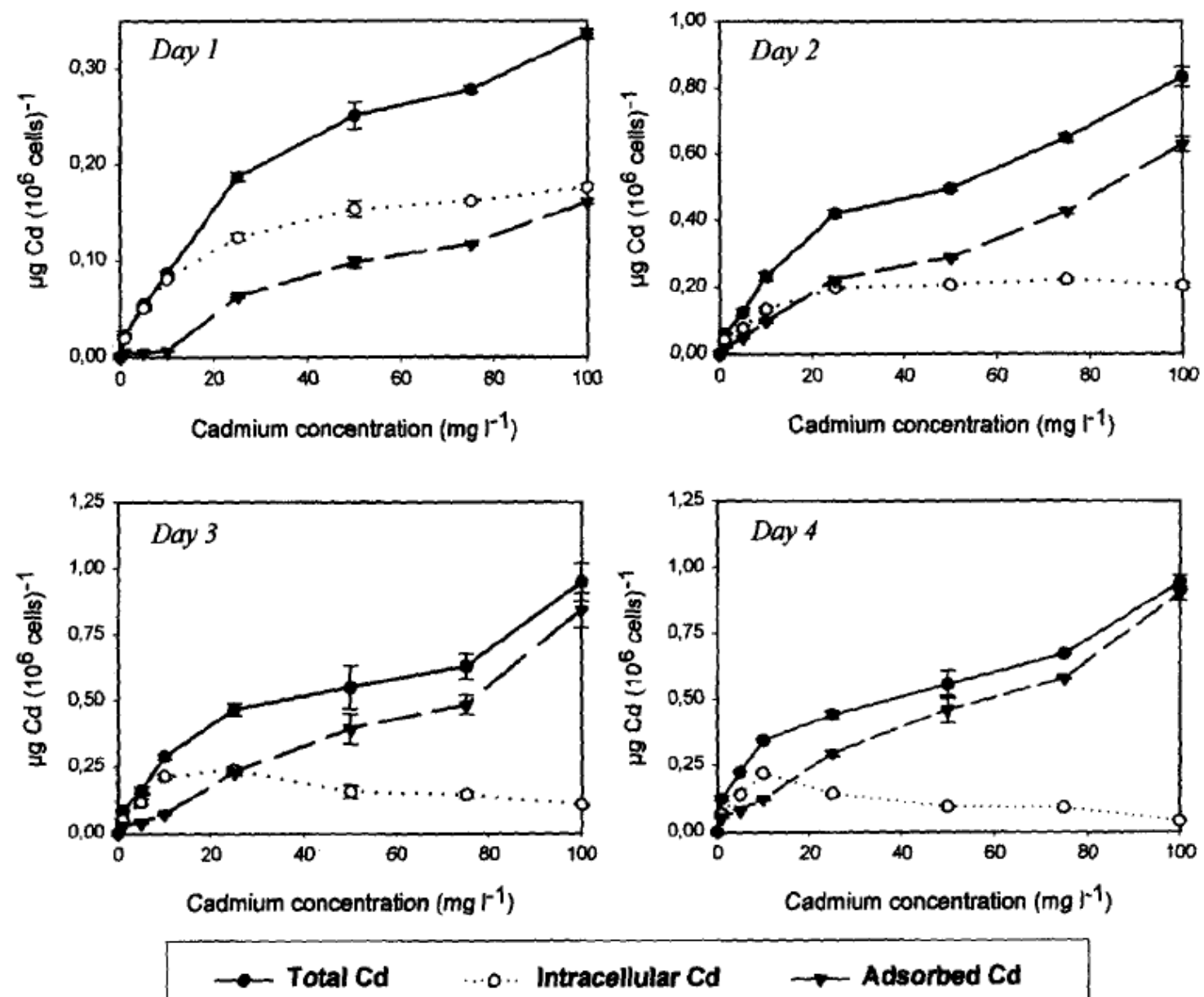

.... Intracellular Cd

Adsorbed Cd

Fig. 5. Cadmium removed in the different cell fractions as a function of the concentration of cadmium in the medium for each day of exposure: •, total cadmium; ○, intracellular cadmium; $\mathbf{\nabla}$, adsorbed cadmium.

\section{Discussion}

As shown in Fig. 2, the kinetics of cadmium removal by $P$ tricornutum cells differed between the various concentrations of cadmium in the medium. At low external cadmium concentrations $\left(<25 \mathrm{mg} \mathrm{l}^{-1}\right)$, total cadmium removal was linear so that the cadmium concentration in the cells increased linearly with time of exposure and was directly related to the external concentration of the metal. This linear increase in total cadmium removal with time of exposure at lower cadmium concentrations suggests that the cells were metabolically active throughout the culture period; thus, at these concentrations, the rate of cell growth was greater (Table 1). However, at 
higher cadmium concentrations, the linear increase occurred only until day 2 because at these concentrations and exposure time, an equilibrium was reached. Similar patterns have been obtained for other heavy metals and for other microalgal species (Garnham et al., 1992; Gnassia- Barelli and Romeo, 1987; Jennings and Rainbow, 1979; Li, 1980; Schulz-Baldes and Lewin, 1976).

As is the case with other metals, the accumulation of cadmium by microalgal cells is a two-step process. First, there is a rapid energy-independent phase inwhich cadmium is adsorbed onto the surface of the algal cells (biosorption), then cadmium is taken up into the cells (bioaccumulation). Bioaccumulation is a process which can be energy-dependent (active transport) or not (passive transport), but in a large number of species of algae and fungi, uptake of cadmium has been reported to be more significantly energy dependent (Hu et al., 1996; Ingvar and Myklestad, 1980; Kwan and Smith, 1991).

Within the first few minutes $(5-40 \mathrm{~min})$ of exposure to cadmium, most of the metal removal by microalgal cells takes place by biosorption, because most of this metal can be released by EDTA (Khummongkol et al., 1982; Sakaguchi et al., 1979). Following this phase, cadmium is taken up into the intracellular medium. The amount of cadmium accumulated within $P$. tricornutum cells after 1 day of exposure was higher than that adsorbed onto the surface for all cadmium concentrations assayed (Fig. 5(a)). This result is in accordance with Gadd and Griffiths (1978) who found that the amounts of heavy metals taken up by passive mechanisms and bound on the surface of algal cells were quite low compared with those taken up by metabolic or energy-dependent processes, and therefore accumulated into the cell.

However, after 2 days of cadmium exposure, the situation was different with cadmium removal by adsorption to the cell surface starting to exceed intracellular cadmium in cultures with concentrations of $25 \mathrm{mg} \mathrm{l}^{-1}$ or more (Fig. 5(b)). This difference increased as the concentration of cadmium in the medium increased. This is in accordance with the decline in the cadmium removed by uptake into the cells (Fig. 3). The decline in intracellular accumulation at cadmium concentrations exceeding $25 \mathrm{mg} \mathrm{I}^{-1}$ was probably due to the severe toxic effects of cadmium on $P$ tricornutum. This effect became greater as the cadmium concentration and time of exposure increased. This seems to indicate that the removal of cadmium by uptake into the cells is mainly an energy-dependent process, because cadmium toxicity to cell metabolism provokes the reduction of cadmium uptake. Thus, the difference between cadmium removal by adsorption and by intracellular accumulation was also higher as the cadmium concentration and time of exposure increased (Fig. 5(c) and (d)). The decline in intracellular cadmium suggests an important loss of cadmium by damaged cells. Cadmium toxicity at high concentrations causes the death of $P$. tricornuturn cells and the release of intracellular cadmium. In this situation, the damaged or dead cells can take up the EDTA into the cell and release the intracellular cadmium. Therefore, this cadmium was measured as adsorbed cadmium. This explains why the adsorbed cadmium increased so much in the higher cadmium concentrations as the time of exposure increased (Figs 3 and 4). 
As can be observed from Fig. 4, an equilibrium in the adsorbed cadmium curves is reached, especially in cultures with a cadmium concentration of $>25 \mathrm{mg} \mathrm{l}^{-1}$. This equilibrium is proportional to the external cadmium concentration because as the cadmium concentration increased, the amount of cadmium removed at equilibrium was higher. This is in accordance with the fact that the main mechanism involved in the removal of cadmium by adsorption is a process dependent on a concentration gradient, that is, dependent on the value $\left([\mathrm{Cd}]_{\text {ext }}[\mathrm{Cd}]_{\text {int }}\right)$.

Thus, at high cadmium concentrations $\left(>25 \mathrm{mg} \mathrm{l}^{-1}\right)$, the removal process depends almost exclusively on a driving force proportional to $\left.\left([\mathrm{Cd}]_{\text {ext }}[\mathrm{Cd}]\right]_{\text {int }}\right)$. This force is not a metabolismdependent mechanism, and for this reason this process predominated at higher cadmium concentrations in which the cadmium was more toxic and the intracellular cadmium accumulation mediated by metabolic processes was very low.

Figure 2 is similar to Fig. 4, although Fig. 2 shows the total cadmium removed and Fig. 4 only the cadmium fraction removed by biosorption to the cell surface. This similarity can be explained by the fact that the absorbed cadmium predominated over intracellular cadmium on most of the days and for most of the cadmium concentrations (Fig. 5); in this way, adsorbed cadmium modulated the form of the total cadmium curves.

In environmental applications, most of the methods for removal of metals are chemical processes (precipitation, filtration, electrochemical treatments, etc.) which are ineffective or extremely expensive when the metals are dissolved in large volumes of solution at relatively low concentrations (1-100mg I ${ }^{-1}$ ) (Volesky, 1990). Microalgal cells could act by means of the bioaccumulation process when the metals are at low concentrations. Two ways for the elimination of metals by algal biomass have been proposed: living algae and non-living algal biomass. Non-living biomass has the advantage that it can be regenerated for multiple uses, but it has the disadvantage that there is no uptake of the metals into the cells, since metals are adsorbed only at the algal surface (Fehrmann and Pohl, 1993). Thisdisadvantage is very important because at lower cadmium concentrations in the medium most of the cadmium removed was within the cells (Fig. 5) and with non-living biomass this process cannot be carried out and the amount of cadmium removed will be low. Therefore, non-living biomass must be used when the concentration of cadmium in the medium is high and toxic for the organism employed. The ability of cadmium accumulation by marine algae depends on the species and on their sensitivity to the metal. If the organism is very tolerant to the toxic effects of cadmium, it can be used with relatively higher cadmium concentrations. Phaeodactylum tricornutum is a microalga very tolerant to cadmium. Its growth is only inhibited at cadmium concentrations of 5 $\mathrm{mg} \mathrm{I}^{-1}$ or higher. This tolerance allows its use as living biomass to remove more cadmium when the cadmium concentration in the medium is low and most chemical methods are ineffective.

Class III metallothioneins, molecules which play a role in cellular detoxification by sequestering the heavy metals in a harmless form, are induced in $P$. tricornutum cells after exposure to 
cadmium (Maita et al., 1988; Torres et al., 1995). These molecules enable P. tricornutum cells to bind more cadmium in the intracellular medium and tolerate high cadmium concentrations.

\section{Conclusion}

Phaeodactylum tricornutum biomass can serve as a basis for the development of a biosorbent material for removing cadmium. It could be highly efficient and cheap, and thus compete with commercial resins and other biosorbents. Phaeodactylum tricornutum has a high ability to remove and accumulate cadmium from seawater. It has a great tolerance to the toxic effects of cadmium, which makes it a suitable monitoring organism for cadmium in marine areas. The concentration of cadmium removed is proportional to the concentration of this metal in the solution. Therefore, when the concentration of cadmium is higher, $P$ tricornutum cells are able to accumulate more metal, until they reach a level at which the toxic effects determine a reduction in the uptake. At low cadmium concentrations the metal is mainly removed within the cells, for this reason the use of living cells is necessary to obtain high efficiency when the cadmium concentrations are low.

\section{Acknowledgements}

This study was supported by the Conselleria de Educaci6n, Xunta de Galicia, Spain, reference XUGA 10301B93. E. Torres holds a Fellowship from the Plan Nacional F.P.I. Ministerio de Educación y Ciencia, Spain.

\section{References}

D.J. Bonin, M.R. Droop, S.Y. Maestrini, M.-C. Bonin

Physiological features of six micro-algae to be used as indicators of seawater quality

Cryptogamie, Algologie, 7 (1986), pp. 23-83

C. Fehrmann, P. Pohl

Cadmium adsorption by the non-living biomass of microalgae grown in axenic mass culture

J. Appl. Phycol., 5 (1993), pp. 555-562

D.J. Finney

Probit Analysis

Cambridge University Press, London, UK (1964)

G.M. Gadd, A.J. Griffiths

Microorganisms and heavy-metal toxicity

Microb. Ecol., 4 (1978), pp. 303-317 
G.W. Garnham, G.A. Codd, G.M. Gadd

Kinetics of uptake and intracellular location of cobalt, manganese and zinc in the estuarine green alga Chlorella salina

Appl. Microbiol. Biotechnol., 37 (1992), pp. 270-276

M. Gnassia-Barelli, M. Romeo

Uptake of zinc by cultured phytoplankters Hymenomonas elongata

Dis. Aquat. Org., 3 (1987), pp. 45-49

S. Hu, C.H. Tang, M. Wu

Cadmium accumulation by several seaweeds

Sci. Total Environ., 187 (1996), pp. 65-71

E. Ingvar, S. Myklestad

Long-term uptake and release of heavy metals by Ascophyllum nodosum (L.) Lejol.

(Phaeophyceae) in situ

Environ. Pollut. Ser. A, 23 (1980), pp. 19-28

J.R. Jennings, P.S. Rainbow

Accumulation of cadmium by Dunaliella tertiolecta Butcher

J. Plankton Res., 1 (1979), pp. 67-74

D. Khummongkol, G.S. Canterford, C. Freyer

Accumulation of heavy metals in unicellular algae

Biotechnol. Bioeng., 24 (1982), pp. 2643-2660

K.H.M. Kwan, S. Smith

Some aspects of the kinetics of cadmium and thallium uptake by fronds of Lemna minor L.

New Phytol., 117 (1991), pp. 91-102

W.K.W. Li

Cellular accumulation and distribution of cadmium in Isochysis galbana during growth inhibition and recovery

J. Plankton Res., 2 (1980), pp. 283-294

Y. Maita, S. Kawaguchi, K. Tada

A metal-lothionein-like protein induced in a diatom, Phaeodactylum tricornutum

Red Tides: Biology, Environmental Science and Technology, Elsevier, Science, NY (1988), pp. 345-348

I.S. Ross

Uptake of heavy metals by micro-organisms

Int. Ind. Biotechnol., 6 (1986), pp. 184-188

T. Sakaguchi, T. Tsuji, A. Nakajima, T. Hosikoshi

Accumulation of cadmium by green microalgae

Eur. J. Appl. Microbiol., 8 (1979), pp. 207-215

M. Schulz-Baldes, R.A. Lewin

Lead uptake in two marine phytoplankton organisms 
Biol. Bull., 150 (1976), pp. 118-127

J.L. Stauber, T.M. Florence

The influence of iron on copper toxicity to the marine diatom Nitzschia closterium (Ehrenberg) W. Smith

Aquat. Toxicol., 6 (1985), pp. 297-305

E. Torres, A. Cid, P. Fidalgo, C. Herrero, J. Abalde

Tolerance and detoxification mechanisms in marine diatom Phaeodactylum tricornutum exposed to cadmium

J. Mar. Biotechnol., 3 (1995), pp. 176-178

B. Volesky

Removal and recovery of heavy metals by biosorption

B. Volesky (Ed.), Biosorption of Heavy Metals, CRC Press, Boca Raton, FL (1990), pp. 7-43

G.H. Wikfors, R. Ukeles

Growth and adaptation of estuarine unicellular algae in media with excess copper, cadmium or zinc, and effects of metal-contaminated algal food on Crassostrea virginica larvae

Mar. Ecol. Prog. Ser., 7 (1982), pp. 191-206

H.-B. Xue, L. Sigg

Binding of $\mathrm{Cu}(\mathrm{II})$ to algae in a metal buffer

Water Res., 24 (1990), pp. 1129-1136 